\title{
Entrevista com o Prof. Dr. Naomar Monteiro de Almeida Filho' (UFSB) realizada em 27/6/2017
}

\author{
por Antonio Augusto Passos Videira (UERJ) e Carlos Fils Puig (UERJ)
}

Recebido em 07/09/2017

Aceito em 16/11/2017

[A.A.] - Como você avalia o projeto lá no Sul da Bahia? Eu li os documentos que estão na página, a Carta de Fundação e o outro...

[N.] - O Plano Orientador.

[A.A.] - O Plano Orientador, exatamente. Foi assim, eu resolvi lhe mandar umas perguntas um pouco genéricas, porque, como eu não sou um especialista, por mais que eu conheça, já até tenha lido alguma coisa do Anísio Teixeira, do Pierre Levi e outros ali, eu não sou um estudioso do assunto. Então, não quis fazer uma entrevista mais teórica, porque podia soar algo vazio, não é? A ideia é conversar com você em torno dessas perguntas, que são genéricas, como eu disse, para tentar não apenas compreender o projeto, mas como você vê esse projeto e quais são os alcances que ele pode ter.

E, no caso da UERJ, e essa é a última coisa que eu queria falar, é interessante para nós, porque a UERJ de 2000 e poucos para cá, fez uma opção claramente por incorporar uma dimensão social. Não é mais uma extensão no sentido clássico, é uma extensão que é, eu diria, social. Então, por exemplo, qual o grande problema da universidade hoje em dia? Não sei se você sabe, os cotistas da UERJ, seja os de raça ou econômico, eles viraram cotistas sociais. Com isso, o governo do estado paga uma bolsa-permanência para os bolsistas. Só que o estado não está repassando esse dinheiro. Repassa com muita irregularidade,

1 Professor Titular de Epidemiologia no Instituto de Saúde Coletiva da UFBA. Médico, Mestre em Saúde Comunitária, Ph.D. em Epidemiologia. Doctor of Science Honoris Causa, McGill University, Canadá. Professor Visitante nas seguintes universidades: Universidade da Carolina do Norte, em Chapel Hill, Universidade da Califórnia em Berkeley, Universidade de Montreal e Universidade Harvard. Primeiro Titular da Cátedra Juan Cesar Garcia da Universidad de Guadalajara, México; Professor Convidado da Maestría en Epidemiología da Universidad Nacional de Lanús, Argentina. Atividade científica: epidemiologia de transtornos mentais, particularmente o efeito de raça, racismo, gênero e classe social sobre a saúde mental. Em sua produção acadêmica, destaca-se uma série de livros-texto sobre o método epidemiológico: Epidemiologia \& Saúde (com Zélia Rouquayrol, Rio de Janeiro: Guanabara-Koogan, 6. ed. 2003); Introdução à epidemiologia (com Zélia Rouquayrol, Rio de Janeiro: Guanabara-Koogan, 4. ed. 2006); Epidemiologia \& Saúde: Fundamentos, Métodos, Aplicações (com Maurício Barreto, Rio de Janeiro: Guanabara-Koogan, 2011); e sobre aspectos epistemológicos da epidemiologia e do campo da Saúde Coletiva: Epidemiologia sem números (em português, Rio de Janeiro: Campus, 1989; tradução em espanhol, Buenos Aires: Paltex/Opas, 1992); A clínica e a epidemiologia (Rio de Janeiro: Abrasco/APCE, 2. ed. 1997); A ciência da saúde (São Paulo: Hucitec, 2000); La ciencia tímida: ensayos hacia la deconstrucción de la epidemiología (Buenos Aires: Editorial Lugar, 2000); O que é Saúde? (Rio de Janeiro: Fiocruz, 2011); Saúde coletiva: teoria e prática (com Jairnilson Silva Paim, Rio de Janeiro: Medbook, 2014). Foi Reitor da Universidade Federal da Bahia de 2002 a 2010. Desde então, tem focalizado sua produção acadêmica em estudos sobre a universidade e sua relação com a sociedade, destacando-se os seguintes livros: Universidade Nova: Textos Críticos e Esperançosos (Brasília: Editora UnB, 2007), Memorial da Universidade Nova: UFBA 2002-2010 (Salvador: Edufba, 2010), em co-autoria com Boaventura Sousa Santos, A Universidade no Século XXI: Para uma Universidade Nova (Coimbra: Almedina, 2008) e, em co-autoria com Fernando Seabra Santos, A Quarta Missão da Universidade (Coimbra: Editora da Universidade de Coimbra, 2012). Foi Presidente da Comissão de Implantação e, até muito recentemente, foi Reitor pro-tempore da Universidade Federal do Sul da Bahia, cargo que ocupava na altura em que concedeu esta entrevista. 
está com atraso, como é o caso dos salários. E a universidade demorou a começar por conta disso, porque não tem como esses bolsistas se manterem na universidade sem o auxílio.

Hoje em dia, se não me engano, nós somos 30 mil alunos no total, contando com os do colégio de aplicação. Cerca de $25 \%$, ou um pouco mais, estão nessa categoria de cotistas sociais que recebem o apoio financeiro do estado, que não vem acontecendo, que não vem sendo efetivado. E a universidade, como fica nisso? Nós temos orgulho de dizer que somos pioneiros e agora... está assim... Então, para nós, também é interessante conhecer um pouco a sua experiência lá, o que você tem a dizer, porque, pelo que eu pude compreender por esses documentos, a Federal do Sul da Bahia também tem essa preocupação. Não exatamente como a da UERJ, mas de ser claramente um elemento, um vetor de desenvolvimento, sob todos os aspectos, como está muito bem exposto nos documentos, naquela região. O que a UERJ não quer, aparentemente, até onde eu posso ver. É um pouco por aí que estávamos querendo conversar com você.

[N.] - Não, tranquilo, eu dei uma olhada nas perguntas e agora esse seu comentário me esclarece ainda mais aí as questões. Enfim, pode, até por efeito de concluir uma entrevista com estrutura de entrevista, seguir aqui as questões, mesmo que depois a gente refaça as questões.

A primeira, quais são os principais problemas enfrentados atualmente pelas universidades brasileiras, em particular as públicas? Eu estou entendendo que é uma demanda de uma avaliação da educação superior no Brasil.

\section{[A.A.] - Isso.}

[N.] - Para constituir o projeto da universidade, mais ou menos durante um ano ou um ano e meio, fizemos um trabalho de prospecção e de estudo e apreciação de modelos, e também avaliação da conjuntura nacional da educação superior. Isso, eu acredito, permite até ser bastante objetivo nesta questão. O Brasil tem uma concepção de universidade que não é própria, é uma concepção trazida, uma concepção colonizada de universidade, referida muito diretamente, no seu início na educação superior, ao modelo português, de Coimbra, e ao modelo francês. O modelo português, que gera as nossas primeiras escolas superiores oficiais, com a vinda da família real, é um modelo que era medieval e já superado pelas universidades europeias. Então, pegamos um modelo muito anacrônico na sua própria realidade, onde a reforma de Pombal não alcançou. O que conseguiu foi retirar os jesuítas do cenário, mas não teve um processo de modernização semelhante à universidade prussiana na universidade lusitana. A primeira matriz é essa, e é uma matriz que no Brasil assume um formato militar. As escolas de medicina eram escolas militares. E eram de cirurgia. Em Portugal ainda tinha a distinção entre cirurgia e medicina. Essa primeira raiz é muito da colonização portuguesa.

Só que Portugal, culturalmente, torna-se rapidamente uma colônia francesa. Do ponto de vista de toda a influência ideológica, da corte e a própria política do Império brasileiro, em especial do segundo império, é diretamente ligada a Paris. Então, tivemos, em todo o século XIX, uma emulação da universidade francesa, que não era universidade. Napoleão extingue... A Revolução Francesa extingue as universidades. Napoleão consolida esse modelo de faculdades e academias. Aí o Brasil copia as faculdades e academias, não é? Quando, já no século passado, temos a motivação no Brasil de organizar a educação superior, o modelo é um aglomerado de faculdades: a missão francesa na USP e aqui, no Rio, o primeiro rechaço da experiência de Anísio Teixeira da Universidade do Distrito Federal e, em seguida, na Universidade do Brasil. E o modelo era este: juntar faculdade de medicina, de direito, a politécnica, criar uma faculdade de letras e a partir daí se construir a universidade mais no modelo da recuperação francesa, da Sorbonne, que era esse modelo de faculdades isoladas e tal.

Esse modelo, a reforma que os militares tentaram em 68 não teve potência política para fazer isso em geral. Fizeram acrescentando a pós-graduação. Então temos uma pós-graduação que tentou copiar o modelo norte-americano de pós-graduação, mas sem modificar a graduação. Aí temos uma série de invenções nesse processo que resultaram nesses acordos e nessa impossibilidade de se fazer uma reforma mais profunda. 
[A.A.] - Só uma coisa de esclarecimento, você diz que os militares não conseguiram mudar a graduação, mas, por exemplo, até... Bom, eu não estudei nessa época, mas, pelo que eu sei, até 68, digamos assim, uma data um pouco fictícia, era seriado e não semestral. Por exemplo, as graduações e licenciaturas eram anuais e não semestrais, não é? É curioso, porque, em geral, me parece que teria ocorrido uma transformação, houve a extinção das cátedras, os departamentos foram criados, isso teria causado certo efeito na graduação. Porque o que eu ouço dizer, claro, aí são relatos pessoais, é que houve uma atomização. Por isso acho curioso você falar que não...

[N.] - Mas a estrutura curricular da graduação brasileira se manteve com a entrada direta, principalmente esse aspecto. No Brasil, a entrada é direta nas profissões. Não existe o college, o undergraduate, o primeiro ciclo, que na Europa do Norte já existia e, nos Estados Unidos, desde o início do século XX.

Isso não se conseguiu, apesar de ter havido tentativas muito firmes, a da própria $\mathrm{UnB}$, onde implantaram um modelo desse tipo. A extinção da cátedra, eu acho que é uma extinção nominal, porque o catedrático ganhou uma equivalência com o professor titular. Mas como o Brasil manteve a ideia de o titular ser um sujeito em cada segmento, em cada pedaço dessa segmentação, e vitalício, porque funcionário público alcança aquela posição e a partir daí só sai na aposentadoria. O que se modificou é que o catedrático era por direito o líder. Isso, ele precisou conquistar depois que se tornou titular, mas a atomização com base nas disciplinas foi reforçada e o aspecto vitalício foi substituído pelo estatutário, concurso público estatutário, que termina sendo vitalício. Só recentemente, no penúltimo plano de carreira, é que se criou a figura do titular como aquele final da carreira do professor nas federais. E, a partir daí, todos os sujeitos que completam a sua carreira têm essa prerrogativa de fazer esse último concurso. Acho que isso, de alguma forma, aproxima o modelo brasileiro do professor titular pleno, como é nos Estados Unidos, por exemplo, onde, nos departamentos mais avançados, todos são titulares. As outras classificações são degraus para se chegar ao professor pleno, não? Diferente da Europa, onde ainda há as cátedras, na Alemanha você tem ainda inclusive com a terminologia.

Então fizemos essa prospecção, só para terminar o fio, não foi para o projeto da Federal do Sul da Bahia somente, é que fui reitor da Federal da Bahia, e lá implantamos, na transição do primeiro ao segundo mandato, um projeto, aproveitando o REUNI, de reestruturação curricular. E, para isso, avaliamos esse cenário. Também estudamos experiências de outros países. Principalmente um, que tenho familiaridade maior, que é o modelo norte-americano, inclusive pela constatação de que o Brasil tem uma dependência de formação em muitas áreas, em especial em áreas de ciência muito avançada, onde há um intercâmbio no topo, mas os sujeitos não vivenciam o sistema norte-americano. Alguém pode fazer, por exemplo, um sanduíche nos Estados Unidos, ou um pós-doutorado, e não avalia, não é capaz de avaliar o que acontece fora do laboratório. Até o próprio conceito da bolsa sanduíche é muito restritivo, é um conceito que... Você faz seu curso aqui, mas vai aprender uma certa técnica num laboratório lá, e esses laboratórios na universidade americana são muito isolados. Então temos uma massa de docentes no Brasil que, apesar de uma relação em termos de rede científica muito estreita, não tem vivência no sistema universitário externo. Aliado a isso também uma característica que eu acho que a universidade brasileira é muito... Em especial a universidade pública, o sistema público, uma dissociação do sistema de educação em geral.

A educação básica, mesmo a passagem, é uma passagem colocando um tipo de cancela, uma demarcação, que é o antigo vestibular, agora o Enem, mas é um processo seletivo muito duro. E pouco retorno das instituições públicas, as instituições universitárias públicas para o sistema de educação público. A maior parte dos sujeitos, por exemplo, que se formam como docentes na licenciatura nas universidades públicas não vão para o setor público de educação. Com todos os pesares, é um nível de qualificação melhor, e o setor privado, competitivamente, puxa esse sujeito. E também, como a comunidade universitária brasileira não é tão grande, as universidades cumprem também um papel de autorreprodução. Por exemplo, você é da área de física, história da física, a proporção de pessoas que se formam na licenciatura ou no bacharelado em física no Brasil é minúscula, e serve para a reprodução, eles se tornam professores daqueles departamentos, daqueles locais. Então temos na universidade pública, em especial, uma relação de distanciamento do sistema de educação em geral. 
E tem muito mais, é um sistema muito complexo esse sistema brasileiro, porque nós nos especializamos em reformas, digamos, parciais. Reforma uma parte, outra e tal, então temos um sistema muito desigual. Por exemplo, a não integração entre a graduação e a pós-graduação é um negócio que não se vê em nenhum outro parque universitário do mundo. Parque avançado, evidentemente, onde os sujeitos estão em uma universidade que é a da graduação com regras inclusive distintas da universidade que é a pós-graduação, na mesma instituição. É muito raro você ter experiências de integração interníveis, nas quais, por exemplo, os alunos de graduação são proibidos de atuarem, ou participarem no nível da pós, e muitas vezes é considerado até uma humilhação você recomendar a um orientando seu na pós-graduação que faça um curso na graduação. E em certas áreas, que muitas vezes você tem o recrutamento de alunos que precisam de um grau de preparação, se faz uma repetição na pós-graduação, em nível pelo menos equivalente, de conteúdos que na graduação estão postos. Na minha área mesmo, a epidemiologia introdutória nos mestrados em geral é no mesmo nível da graduação. Mas aí o sistema é tão dissociado que lhe obriga a ter uma disciplina de introdução à epidemiologia na graduação e outra na pós-graduação com níveis equivalentes. Às vezes até o nível na pós-graduação não é tão operacional ou exigente quanto na graduação. Esse é outro aspecto que eu acho que caracteriza o sistema brasileiro.

Temos também, e aí é uma crítica mais do ponto de vista político, um pacto histórico de formação de elites nas universidades públicas. Isso faz com que as instituições sejam muito dirigidas para se preparar para projetos individuais, projetos de vida individuais, em uma estrutura que, na graduação, é claramente profissionalizante. As universidades públicas em geral têm um sistema de recrutamento que reproduz, intensifica e consolida uma perversão, na qual os cursos de maior demanda social, de mais prestígio, se não fossem as políticas reparativas ou compensatórias, tendencialmente seriam sistemas de formação justamente de sujeitos que pertencem às elites dirigentes do país. Aí você tem o paradoxo da instituição pública gratuita estar povoada, com todas as nuances aí, mas fundamentalmente voltada para a formação desses quadros de elite. Enquanto que para aqueles que conseguem buscar educação superior superando dificuldades vindo de camadas populares, resta o ensino privado. E aí é o paradoxo, pois quem pode pagar entra na instituição gratuita, de melhor qualidade, e quem não pode pagar entra na instituição que tem que pagar, que é privada e de menor qualidade. Então, realmente é uma complexa perversão, um sistema de paradoxos, que têm explicação pela funcionalidade e tal.

Ao avaliarmos esse cenário nacional e também de outros países, e considerando o aspecto absolutamente necessário de políticas públicas reparatórias, compensatórias, ações afirmativas, como a UERJ é pioneira, mas também a Federal da Bahia, entre as federais foi também desse primeiro grupo, o desafio para nós foi avaliar de que forma a estrutura da universidade poderia ser mais atuante para essa integração de segmentos sociais excluídos. Porque o sistema de reserva de vagas, quotas ou bônus, é um sistema que mantinha inalterado o sistema excludente da instituição. Produzindo inclusive problemas de operação, como esse que você estava mencionando aqui, e nas federais também - o programa nacional de assistência estudantil está ameaçado por cortes.

O que buscamos para construir o conceito da Universidade Federal do Sul da Bahia? Que na arquitetura curricular se incorporassem uma série de estruturas e soluções que produzissem esse impacto social no território de modo que as políticas de ações afirmativas se tornem salvaguardas, garantias, mas que a própria estrutura fosse socialmente inclusiva. O conceito mesmo de territorialidade da instituição é uma territorialidade muito prática. Por exemplo, identificamos que nas universidades novas, ou nos campi interiorizados com essa expansão recente, um fenômeno constatado é a ocupação de vagas por sujeitos de fora do território. É evidente que aqui no Rio de Janeiro isso não acontece, porque o Rio já tem sua gravidade própria, mas numa cidade como Itabuna, por exemplo, onde a estadual de Santa Cruz criou um curso de medicina, que conseguiu muito bons resultados, um curso bem-feito, um alunato pequeno, se celebra quando alguém da região consegue entrar na instituição. E a cultura brasileira tem muito de uma fixação de laços familiares próximos do local de nascimento. É diferente de outras culturas em outros países. Isso produz uma referência tendencial para a instituição, uma referência externa, quer dizer, o aluno passa ali, faz o seu curso inteiro e, quando termina, volta para a sua região, vai se formar em outro lugar, mas os episódios de fixação de profissionais no território da instituição são raros e pouco frequentes. 
Por último, também identificamos no sistema universitário brasileiro uma terrível burocratização. Deve ser um dos segmentos mais barrados por sistemas de regulação, muitos deles insensatos, e que, no caso especial das instituições públicas, muito vulneráveis à judicialização. Os concursos públicos são concursos muito arcaicos, as regras de entrada dos sujeitos são regulamentadas por externalidades jurídicas, a eficiência que se espera encontra um sistema de controle que é absolutamente insensato. Todo mundo tem um exemplo de alguma burocracia absolutamente desnecessária, repetitiva, pouco criativa e que tira a energia do sistema de produzir o que se espera dele, que é originalidade, criatividade, ineditismo, extensão, qualidade. Tudo isso encontramos na educação superior nacional, apesar de uma burocratização que realmente desafia as regras da lógica.

Esse cenário, esse diagnóstico que fizemos junto com prospecção de outros modelos, permitiu uma solução, ou pelo menos uma proposição de criar uma instituição, aproveitando o fato também fortuito de que, dentre as universidades federais novas, ou novíssimas, como estão chamando agora, que são as quatro últimas, a nossa foi a única criada a partir do zero. Normalmente as universidades no Brasil são criadas por agregação de escolas, institutos ou faculdades isoladas, ou por desmembramentos de campi, ou de extensões, e a nossa não. Não tinha nenhuma oferta, nenhuma organização ou instituição oferecendo vagas federais de educação superior num raio de 500 quilômetros. Tivemos a oportunidade de produzir um desenho e de até seguir um plano lógico. Por exemplo, discutimos, primeiro, valores. A carta de fundação é um documento que lança a questão dos valores, a missão da instituição, a razão de ser, como dizemos ali. Em seguida, tivemos tempo para fazer um projeto. Eu acho que não tem... Deve ter algum exemplo de outras instituições, mas são exemplos realmente pequenos, ou em pouco número, dessa sequência. Em terceiro lugar, modelos do plano orientador. Em seguida, dispositivos que, aí sim, dispositivos já mais de regulação, tipo estatuto e resoluções, regimentos e tal. Essa circunstância permitiu, no caso, a proposição de uma série de inovações.

A sua segunda pergunta é a questão da criação, e a questão vem com a iniciativa de criar. Na verdade, essa região tem uma carência muito demonstrada, é uma região de 1,5 milhão de habitantes, 48 municípios, e muito pouco servida de educação superior pública. Eu acho que era uma tendência de se posicionar um projeto dessa natureza ali, no sul da Bahia. A questão é o momento político, que já foi posterior ao REUNI, num momento em que a expansão já foi mais reduzida e com muitos compromissos assumidos pela rede federal em especial para investimento, mas acredito que foi uma acomodação mais tardia no processo de expansão. Tanto que as quatro novíssimas, duas são na Bahia. Uma no oeste da Bahia, por desmembramento do campus que implantamos no REUNI em Barreiras. Uma no Cariri, com o desmembramento do campus da Universidade Federal do Ceará, e a outra no sul e no sudoeste do Pará, com o desmembramento de campi, aí no caso mais de um, da Federal do Pará. A nossa foi a única, como eu disse, que não tinha nenhuma representação institucional ali, e foi essa circunstância que permitiu ao projeto incorporar soluções para alguns dos problemas que prospectamos.

Quem participa desse início? Foi constituída uma comissão de implantação pelo MEC. Não ainda pelo MEC, mas pela Universidade Federal da Bahia, que foi indicada pelo MEC para ser a instituição tutora. Isso foi no meio do ano de 2013. Em 2012 já tínhamos prospecções nessa direção, pelo fato de que o governo federal encaminhou o projeto de lei para o congresso nacional. Em final de 2012, começamos a fazer audiências públicas. Claro, já tinha disputas por implantação de campi e começamos a dialogar lá. Eu me incorporo nessa comissão em janeiro de 2012. Na verdade, o projeto de lei foi em 2011, foi encaminhado em 2011, acho que em outubro, ao congresso nacional. Eu me incorporo em 2012. Além de todo esse trabalho de construção conceitual, iniciamos um trabalho de peregrinação pelo território. Eu sou oriundo da região, nasci lá, me criei na região.

\section{[A.A.] - Qual município?}

[N.] - Guararema, que é onde nasci, mas me criei em Itabuna. Fiquei até os 17 anos lá, então, tenho muita familiaridade com o território, mas, ainda assim, para conhecer todos os municípios, deu um trabalho muito grande. Nós já estávamos com uma perspectiva de cobertura territorial mais ampla, identificando que algumas soluções no mundo eram interessantes para que a estrutura da universidade fosse mais inclusiva. 
Estudamos, então, o modelo canadense, do CEGEP, estudamos os Community Colleges, dos Estados Unidos, em especial o da Califórnia, que é o sistema mais bem implantado. Estudamos também a universidade bolivariana, no seu projeto original, com as aldeias, que é um acrônimo para espaços, ambientes, universitários descentralizados nos municípios. Cuba, a partir de 2004, num projeto do próprio Fidel chamado Universidad Nueva, sedes universitárias municipais. Tem mais de 3 mil sedes universitárias municipais. Até em prisões eles têm, são unidades descentralizadas da universidade, com capacidade de mobilização rápida para pegar esses sujeitos dessa fase inicial de formação e redirecionar para setores que a economia e o país precisam. Eles têm isso bem desenvolvido lá.

Ao fazer o reconhecimento do território, encontramos que praticamente não tem nenhuma escola da rede estadual de ensino médio com a sua capacidade totalmente ocupada. Aí veio a ideia de criarmos uma rede descentralizada do que chamamos de "Colégios Universitários", que é um conceito de Anísio Teixeira, que ele tinha concebido originalmente para o projeto da UnB, mas não implantou na UnB. Aparentemente, a posição do Darci Ribeiro venceu, de ter uma universidade clássica com um único campus agregador de tudo. Anísio queria a UnB integrada no plano diretor de Brasília. O conceito de Colégio Universitário era isso; o primeiro ano da universidade ser feito fora dos muros da instituição, articulado à rede de ensino. Vimos a oportunidade de fazer isso na região, aproveitando as instalações ociosas das escolas por causa da evasão do ensino médio. E o distintivo desse projeto em relação a outras inovações foi exatamente essa rede, que chamamos, em homenagem a Anísio Teixeira, de Rede Anísio Teixeira, como está no Plano Orientador. E ser uma universidade, desde o começo, exclusivamente em regime de ciclos. Quer dizer, nenhum aluno entra direto em uma carreira profissional. Ele entra num primeiro ciclo que gradativamente orienta e informa para a tomada de decisão, com um currículo bastante aberto. Praticamente, o aluno constrói o seu próprio currículo a partir de uma série de dimensões de formação geral que habilitam a compreensão desse próprio processo.

Você questiona como foi a recepção por parte da comunidade não acadêmica. Inicialmente, essas audiências públicas eram até monótonas, porque os prefeitos e lideranças políticas queriam saber se era viável o curso de medicina naquele município. Quando não conseguiam o curso de medicina, o curso de direito e, em terceiro lugar, as engenharias. E o nosso diálogo era o seguinte: "Vocês preferem ter fragmentos de um curso que os alunos vêm de fora e ocupam esse curso, e o alunato da cidade não consegue e fica vendo a universidade passar, ou esse outro?" Que é o modelo que apresentávamos e discutíamos e construímos muito em discussão, esse outro modelo que aumenta muito a chance da juventude desse município ou território entrar na universidade e depois avaliar qual carreira vai buscar. Esse diálogo foi muito interessante e terminou com uma espécie de pacto, porque os cursos de segundo ciclo que estavam previstos nos segmentos eram cursos bem delimitados, tipo medicina, saúde, direito, humanidades, e engenharias para ciência, e na área de artes mais aberto, como tínhamos três campi, a negociação foi: "Olha, estabelecemos medicina em um campus, direito em outro campus e as engenharias em outro campus." E com uma avaliação do que aquele território já dispõe.

Por exemplo, não concebemos, em nenhum momento, abrir um segundo curso público de medicina onde estava a UESB, que já tinha um curso de medicina de muito boa qualidade. Assim como o local Teixeira de Freitas, que é um município muito grande, crescendo, num território que não tinha nenhuma formação nesse sentido em saúde, colocamos ali o conceito do Centro de Formação em saúde em Teixeira, os Centros de Formação em humanidades, ciências ambientais e artes em Porto Seguro, e os Centros de Formação em tecnologia e inovação, área mais industrial e ciências agroflorestais em Itabuna. Então, esse pacto foi construído e iniciamos a implantação dos colégios universitários. Iniciamos com oito colégios universitários nesse modelo. A localização dos colégios universitários também muito dialogando com a sociedade no território. Nessa fase inicial, eu diria que, quando iniciamos atividades em setembro de 2014, posso dizer com tranquilidade que o modelo estava absorvido, mesmo com alguma dificuldade de compreensão da complexidade e do pouco intuitivo que é em relação ao que a sociedade brasileira está acostumada, em especial, com a elite já ter o seu espaço mais ou menos reservado para a sua futura geração na universidade pública.

Mas isso foi facilitado - e essa é uma análise que fazemos posteriormente - pela concepção territorial. A classe média e alta da região não disputava espaço da universidade na região. Já tinha os seus projetos... 


\section{[A.A.] - De estudar fora.}

[N.] - ... de mandar para fora, externalizar, de modo que houve até uma compreensão disso, de que esse modelo que estávamos construindo promovia a integração da juventude do território na educação superior, inclusive com um tipo de proteção que era legalmente robusta. Quer dizer, não é uma quota territorial, como algumas universidades buscaram fazer. Chama-se "a reserva de vagas definida pelo CEP". Não é isso. O processo seletivo é: o Colégio Universitário de Guaraci tem trinta vagas, mas um curso que não tem nome, pois é entrar na universidade, na Área Básica de Ingresso. Então, só se interessa por essa vaga quem é de Guaraci e do seu entorno.

Para termos ainda uma salvaguarda mais firme, nós incorporamos as quotas. Só que interpretamos de modo bem amplo a lei das quotas, que as federais são obrigadas a seguir, um mínimo de $50 \%$ de quotas para alunos de escola pública com recortes de renda e de etnia. Nós interpretamos do modo mais amplo possível e colocamos uma quota na rede de Colégios Universitários de $85 \%$, que a lei diz que é mínimo. Podíamos colocar até $100 \%$, pois a lei diz que é mínimo, mas deixamos essa proporcionalidade, pois ela é rigorosamente a proporção de alunos que na região concluem o ensino médio vindos de escola pública, 85\%, restauramos a demografia. Isso demonstrou uma segurança jurídica muito grande, tanto que muitas universidades se queixam de ações judiciais o tempo inteiro, e na nossa não tivemos nenhuma ação judicial nesse processo, seguimos a lei e, ao mesmo tempo, alguém que não venha de escola pública que deseje competir com uma vaga em um Colégio Universitário numa área remota não vai ter problema, tem lá um espaço que essa pessoa pode postular. Mas o resultado é que é praticamente 100\% dos alunos nos Colégios Universitários vêm de escola pública e quase todos da localidade.

[A.A.] - Você falou que nesse município tem trinta vagas, vocês têm uma estimativa de quantos alunos daquela região gostariam de ingressar na universidade? Para saber se há uma demanda que não está sendo atendida?

[N.] - Nós construímos a proposta nessa lógica, tanto que só abrimos Colégios Universitários em locais que tinham mais de trezentos egressos do ensino médio na rede pública da localidade. Mas abrimos para, sendo otimistas, expandir. Iniciamos com trinta vagas, ampliamos para quarenta. Neste momento estamos oferecendo quarenta vagas em cada Colégio Universitário. A competição não é maior do que aquela que buscávamos. Postulávamos, inclusive com um cálculo estatístico, o máximo de três candidatos por vaga. Nós chegamos a certo número ótimo. Uma competição ótima é aquela que você tem três candidatos por vaga - ela não fica ociosa, mas também não é excessivo. Então iniciamos com esse dimensionamento.

Entretanto, a experiência tem demonstrado que, primeiro, a conclusão do ensino médio é menor do que as projeções indicam, em toda parte do sul da Bahia, e muitos não buscam a universidade. Concluem o ensino médio e não buscam a universidade. Recentemente, com o processo de implantação, as etnias indígenas, que são três etnias muito prevalentes na área - aliás, há uma concentração bastante grande na costa brasileira, é uma das maiores, eu creio que deve ser a maior concentração, ali em torno de Porto Seguro, Pau Brasil, são Pataxós Hãhãhãe e Tupinambás -, procuraram muito a universidade. Então criamos vagas supernumerárias para os indígenas. Na seleção anterior tivemos uma concorrência de cinco para um, o que é altíssimo. Isso tem feito avaliarmos uma ampliação dessas vagas supernumerárias nesse último processo seletivo.

\section{[A.A.] - E por que eles procuraram? Por que houve essa procura?}

[N.] - Resulta de uma construção institucional com um processo de governança com a participação da comunidade do território, muito induzida pela universidade. Também, nesse caso, avaliando modelos existentes, e aquele problema que identificamos no sistema universitário brasileiro do distanciamento da sociedade. No nosso estatuto já tem, já é previsto no plano orientador, que temos dois conselhos superiores, um é o Conselho Universitário, que é fundamentalmente acadêmico, não é administrativo; e outro... 


\section{[A.A.] - Sugere, não é?}

[N.] - Sim, mas o que ele delibera é a vida acadêmica: a pesquisa, os programas, os planos de ensino, os projetos de curso, é isso que delibera, e a regulação e regulamentação acadêmica. E temos um Conselho Estratégico Social, que é um conselho superior da universidade. Tem um caráter fundamentalmente consultivo, mas tem uma missão. Na verdade, uma missão dupla: apreciar os planos de desenvolvimento da universidade, e promover um fórum social da região em anos alternados, de modo que criamos um dispositivo que é formado pela sociedade onde a universidade participa. Mas participa minoritariamente, por exemplo, o Conselho Estratégico Social tem 24 membros e 3 são da universidade. O modo de organizar esse conselho segue, de certa forma, um respeito à organização dos segmentos sociais, construídos no fórum.

Fizemos o fórum em 2015, foi o primeiro fórum social, estamos planejando o segundo este ano. Houve três preparatórias, uma em cada campus, convocando os segmentos sociais, que se apresentassem. Cada um deles se organizou em seções autogestionadas, com a regra de levantar moções, apreciar o plano da universidade e propor, sugerir. E com a segunda finalidade, a de eleger delegados para uma plenária final desse fórum. Esse processo foi iniciado. O primeiro realizamos em Itabuna e excedeu as expectativas, tínhamos mais de 600 participantes. Em Porto Seguro chegaram a mais de 800. Segmentos sociais que não tínhamos pensado chegaram e se apresentaram, como os professores da rede pública de ensino. Eles se apresentaram em massa e participaram. Os estudantes secundaristas se organizaram e foram. Quando terminou, nós tínhamos mobilizado mais de 2000 pessoas. Eles elegeram: a cada 5 participantes elegiam um delegado para a plenária final. Terminamos com 399 delegados eleitos por 18 segmentos sociais. Reunimos em Porto Seguro, isso já foi em setembro de 2015, numa plenária que foi realmente fantástica, mais de 1000 pessoas discutindo. Os empresários foram, os trabalhadores rurais, os assentados do MST apareceram, os indígenas - e aí respondendo à sua questão - os indígenas, vendo essa perspectiva, foram em massa. Havia mais de 200 participantes das diferentes etnias nos segmentos do fórum. No de Porto Seguro, principalmente, pela proximidade, eles foram e invadiram a universidade. Nesse sentido, interessante.

Essa experiência, acho que produziu um Conselho Estratégico Social que é representativo da sociedade. Havia lá desde um senhor de uma grande empresa de plantação de eucalipto para celulose, um dirigente do sindicato da hotelaria de Porto Seguro, junto com o coordenador do MST da região com dois caciques indígenas, também a líder de um quilombo muito grande de lá, chamado Helvécia, eleita pela sua comunidade, eles são membros desse conselho. Os indígenas descobriram a universidade e tudo o que ela faz, e eles realmente comparecem em peso.

$$
\begin{aligned}
& \text { [A.A.] - Mas as tensões sociais devem surgir o tempo todo aí. } \\
& \text { [N.] - Sim. }
\end{aligned}
$$

$$
\begin{aligned}
& \text { [A.A.] - Como faz para... Quer dizer, o foco é a universidade e não a sociedade diretamente. } \\
& \text { [N.] - Sim. }
\end{aligned}
$$

\section{[A.A.] - Como faz para criar, não amortecimentos, mas para evitar a divergência e manter a conver-} gência? Como conseguem isso?

[N.] - A universidade tem sido considerada como uma espécie de espaço respeitado. Nunca tivemos realmente nenhum problema dentro da universidade. Muitas vezes a universidade é convocada pelos segmentos que têm dificuldade, em especial os indígenas, pois lá há muito conflito de terras, uma luta muito intensa, e eles pedem ajuda da universidade e nós temos ajudado. Em especial nos aspectos legais, audiências públicas, comparecimentos e tal. Por outro lado, eles também têm ajudado muito a universidade, pois num projeto desses a tensão interna também é grande. Eles têm sido decisivos. Um exemplo, logo que começaram 
os cortes, o movimento principal entre os docentes da universidade era reduzir a entrada. A posição nossa era, "olhe, começamos pequeno, era para ampliar, mas se do pequeno você reduz, o sinal que você está dando para a sociedade é um sinal negativo." Foi um debate muito difícil e o Conselho Estratégico entrou nesse debate muito forte. E, apesar da restrição geral, manteve, para a universidade, uma demanda clara de que não era para encolher, era para avançar.

Então é fato. Quer dizer, a sociedade é complexa, mas acho que esse papel da universidade de catalisar diálogos, acho que está bem entendido e é aproveitado, como já temos exemplos.

\section{[A.A.] - Isso se reflete no ensino e na pesquisa que vocês realizam?}

[N.] - Sim, totalmente. Por exemplo, usamos um dispositivo que está previsto no nosso estatuto, que é o credenciamento de professores que não são docentes do quadro da universidade. Estendemos isso para mestres de saberes populares tradicionais, mestres de ofício, e eles são participantes nesses processos de incorporação da comunidade. Por exemplo, é parte do meu assunto nesse evento que me convidaram, o carpinteiro naval dá aula sobre como fazer barcos para o pessoal de ciências. Os mateiros conhecem as árvores muito melhor do que biólogos especializados. Isso se reflete diretamente no ensino. Algumas dessas demandas têm forçado a universidade a abrir espaços que não eram previstos. Por exemplo, não tínhamos planejado inicialmente Colégios Universitários que depois foram incorporadas no plano. As áreas indígenas, quilombos e assentamentos que passaram a fazer parte do projeto.

[A.A.] - De certa maneira, a incorporação desse docente já tinha sido prevista pelo próprio Anísio Teixeira, pois na UDF não precisava ter formação universitária para ser professor. Tinha que ser um sujeito com conhecimento naquela área, e com produção. Portinari, Villa-Lobos são nomes sempre mencionados. E os alunos recebem bem?

[N.] - Olha, há polêmicas, há polêmicas. Eu diria que temos, grosso modo, três segmentos de alunado. Um é um segmento que entra na universidade já com um projeto pessoal. Fazer um curso de medicina, entrar mais fácil na medicina, entrar mais fácil no direito, fazer engenharia, agronomia, administração, então tem um grupo de alunos que vem com essa perspectiva. Outro grupo são pessoas que não tiveram experiência de universidade e querem vivenciar a universidade, inclusive gente que já teve profissão e se aposentou. Isso é interessante, pois são pessoas mais velhas, mais maduras, gente que tem inquietação e inteligência, mas que não teve chance de entrar numa universidade verdadeira, assim, nesse sentido. E um terceiro grupo é o pessoal que de fato não tem uma ideia pré-concebida e vem para a universidade explorar as possibilidades. Esses três grupos convivem. Com o modelo que utilizamos, eles convivem e isso produz um efeito pedagógico interessante e permite que acionemos dispositivos que se chamam "pedagogias ativas", em que o próprio alunado forma equipes e grupos e em que eles têm um processo de intertutoria, responsabilização mútua e participação. Chamamos de "Equipe de Aprendizagem Ativa". Eu acho, numa avaliação geral, muito positivo.

[A.A.] - Sim, porque lendo o... Eu não quis colocar isso na pergunta, porque confesso que não sabia bem como seria recebido, e eu provavelmente colocaria um tom negativo dada a minha vivência aqui na UERJ. O pressuposto que vocês têm por parte do alunado é um pressuposto, aí vem o tom negativo, que é de uma vontade de aprender, de ser autônomo, de fazer por si próprio, de construir seu caminho, que eu, em geral, não vejo aqui acontecer. É impressionante, quer dizer, não que seja o único, mas um dos mais importantes pressupostos que vocês têm é: se o aluno entrar aqui esperando que vai receber... Não é que $o$ aluno fracassa, o projeto fracassa.

$$
\text { [N.] - Exatamente. }
$$




\section{[A.A.] - Não sei se vi errado.}

[N.] - Mas é isso mesmo. Agora, eu acho que boa parte dessa resposta do alunado é um pacto implícito com o corpo docente. Quer dizer, o corpo docente não está numa estrutura que valoriza a escolha do aluno. O aluno chega, recebe uma grade curricular predefinida, com todos os pré-requisitos, 1, 2, 3, 4, 5, 17, em que o docente já faz aquilo o tempo inteiro, aquele mesmo curso. Ano após ano aquela mesma disciplina em uma base com pouca flexibilidade, isso já provoca uma perda de motivação. Esse modelo do regime de ciclos, que os outros países trabalham com um grau de liberdade grande do aluno no início, tende a produzir um perfil de alunado que já verificamos em outras instituições, como na própria Federal da Bahia, os alunos dos bacharelados interdisciplinares têm um perfil que inclusive incomoda. É um perfil demandante, mais querelante até, num certo sentido, de estar perguntando, querendo e desafiando, que pode provocar tensões também, se você tiver um corpo docente que funcione numa base convencional. Como o corpo docente na universidade convencional funciona numa base convencional, o alunado responde a essa convenção, porque ele já tem todos os signos supostos de que o melhor é se conformar.

Temos experiências muito interessantes de assunção dos alunos e protagonismos. Por exemplo, muito disso é provocado. Você tem uma catálise nesse processo. Vou pegar só um exemplo. No primeiro contato dos alunos com a universidade, tentamos ritualizar a relação desse docente, que tem esse primeiro contato, como um representante institucional, mas se apresentando como pessoa também. Usamos aquela estratégia do memento mori, em um componente curricular que é chamado "Experiências do Sensível". O Daniel [Fils Puig] é um entusiasta da experiência do sensível. Não é uma disciplina, é um conjunto de exercícios de leitura do território em que o professor se apresenta com vários pequenos objetos que significam a sua vida, e fala, "Este aqui é meu primeiro caderno, guardo até hoje, é importante para mim", e distribui. É uma ritualização do sujeito se apresentar com objetos concretos. Passa para os alunos: "Na próxima sessão, tragam como exercício uma amostra de terra e, depois, aqui, vocês vão dizer por que essa amostra de terra é importante na sua vida." No exercício seguinte, amostra de água, amostra de plantas, folhas, sons, todo mundo tem telefone celular agora no Brasil, praticamente, "fotografem seu ambiente e venham aqui dizer por que fotografaram isso."

Essa mobilização ativa produz resultados neles, que gosto de citar sempre, pois acho fantástico. No Colégio Universitário de Guaraci, os alunos levaram amostras de água. Um deles levou amostra do rio que está morrendo e começaram uma discussão sobre o rio morrendo. E se deram conta que moravam ali há duas, três décadas e ninguém nunca tinha pensado onde nasce o rio, de onde vem a água do rio. E resolveram subir o rio para encontrar a nascente do rio. Propuseram como exercício e a universidade apoiou: subiram o rio até a nascente, registraram, eles fazem um portfólio, um blog-portfólio, e registraram. Está na internet a emoção deles de encontrar a nascente do rio.

Por isso buscamos que essas metodologias sejam utilizadas, quer dizer, se tornem um padrão do aluno esperar que a metodologia seja essa. Tem outro efeito, uma solução, que acho também que veio do processo, mas que é muito diferencial. O professor não é responsável por uma turma e uma matéria. Ele faz parte de uma equipe docente. Porque como a rede universitária e os campi estão dispersos no território, o desafio é termos qualidade e conteúdo, abordagem equivalente em todo o território. Então não é um professor, uma matéria, uma turma, um semestre, é uma equipe docente. Isso produz um efeito que incomoda alguns professores. Desde o começo tem gente postulando a liberdade de cátedra, a famosa mitológica liberdade de cátedra. "Professor na sua sala é soberano." Mas no conceito da universidade não é. Você tem um elemento que não só os alunos são incentivados a trabalhar em equipe, mas também os docentes. Isso tem realmente um resultado muito interessante. O terceiro ponto aí nisso é o uso de tecnologia.

[A.A.] - Está bem claro que vocês fazem muito uso. Esse é outro ponto que eu ia colocar, vocês devem ter uma, não digo dificuldade, mas uma preocupação constante quotidiana com a integração desses colégios, dos três campi. Vocês veem algum desnível na estrutura total, ou vocês têm conseguido manter os três polos funcionando adequadamente? De maneira equivalente? 
[N.] - Em termos de função institucional, sem dúvida. Agora tem um elemento que também distingue esse modelo do convencional das outras universidades. Nas outras universidades, a definição da carreira e do destino profissional e acadêmico do aluno se dá na entrada. Quer dizer, passou no vestibular num curso difícil, está feito. No nosso caso, não, eles vão ter que construir um histórico escolar que seja condizente com a postulação que vão buscar, e um coeficiente de rendimento que suporte a competição. Essa sua questão, por exemplo, é levantada porque os alunos de Porto Seguro, que postulam medicina, se queixam que em Porto Seguro eles não estão tendo a preparação suficiente para serem competitivos para entrar na medicina, em função da diferença de professores, porque o centro da saúde está em Teixeira de Freitas, e uma série de argumentos aparecem.

Isso produz um desafio de operação do sistema, mas o próprio elemento - o aluno buscar um aproveitamento é uma distinção quase antagônica ao sistema tradicional, em que o pacto entre o professor improdutivo e o aluno desmotivado não reflete em nada em relação a aproveitamento. Quer dizer, não importa que o aluno aprenda ou não aprenda, no caso de um pacto desse tipo. No modelo que a gente implantou não, o aluno não vai querer o professor que dê nota mais fácil e que ao mesmo tempo não o prepare para os processos competitivos. No caso dos não competitivos, e tem vários, temos trabalhado muito na construção de motivações com externalidades, inclusive pela comunidade. Isso tem efeitos que têm sido avaliados positivamente.

Implantamos a instituição inicialmente em 2014. Nessa primeira turma, tivemos uma taxa de confirmação - porque usamos o SISU - a taxa de confirmação foi bastante alta. Teve, mais ou menos, $70 \%$ de confirmação. Não precisamos rodar tantas listas de espera, ou tantas segundas chamadas, terceiras chamadas como outras instituições. No ano seguinte, a taxa de confirmação aumenta e no terceiro ano aumenta mais ainda. Os escores do Enem também cresceram ano após ano. É claro que tem algumas distorções em função desses cursos que puxam algum sujeito. Mas temos, por exemplo, faixa de Enem de 700, para alunos que postulam BI de saúde, 650 para ciências, 640 para humanidades. Artes é que fica entre 550 e 600 . E área básica de ingresso, que foi também uma solução que encontramos para integrar os Colégios Universitários, só para contextualizar bem: se o Colégio Universitário tem uma entrada mais reduzida de alunos, e como eles ficam dispersos, se os alunos pudessem fazer escolhas prévias ao entrar, você pulverizava a turma. Quatro ou cinco escolhas com um grupo de 30,40, você tem pequenos números. Então, nos Colégios Universitários e nas sedes, os alunos entram sem precisar escolher o curso. Eles entram na Área Básica de Ingresso. Só que, tendencialmente, Área Básica de Ingresso leva à licenciatura interdisciplinar. Mas ele pode, após completar o primeiro ano da formação geral, usar o seu escore para postular uma mudança. Se tiver um escore alto, ele pode até ir para um BI de saúde. Essa certificação na formação geral é uma certificação que quem completa pode sair da universidade, trabalhar, migrar, fazer aquelas coisas que em geral a juventude do interior faz, sem perder o vínculo com a universidade. E retorna com aquele certificado, não precisa ter novo processo seletivo.

\section{[A.A.] - Não tem prazo de validade? \\ [N.] - Tem prazo de validade de dois anos, mas é um prazo de validade razoável.}

\section{[A.A.] - Sim.}

[N.] - Isso permite que flexibilizemos o conceito de evasão. Uma das coisas mais absurdas na universidade brasileira é que ela trabalha o conceito de evasão como sendo em tese negativo. Não se ajusta para criar uma estrutura que seja acolhedora, e sim tem uma estrutura que fomenta a evasão e não reconhece que fomenta a evasão. Esse sistema... Claro, estamos na implantação, testando os efeitos dessas soluções, mas essa acho que é uma das soluções de mais bom senso existente que o mundo inteiro pratica. Mas o Brasil não pratica isso. Eliminamos o conceito de trancamento de matrícula, que é o horror dos colegiados. Não sei na UERJ, mas nas federais os colegiados ficam abarrotados de processos de trancamento de matrícula. 
[A.A.] - Aqui também.

[N.] - Aqui também. Nós não temos trancamento de matrícula. As matrículas são oferecidas, o aluno faz uma pré-matrícula e confirma. Se ele não confirma até a primeira semana de aulas, essa vaga cai e fica disponível para abrirmos para um edital permanente que temos para a sociedade ocupar as vagas não ocupadas nas salas de aula da universidade, com algumas prioridades: professores do ensino médio das redes municipais do território, alunos de outras universidades. Temos, em média, em cada período letivo, de 600 a 1000 alunos que são alunos de inscrição especial.

\section{[A.A.] - Isso cria certa heterogeneidade no corpo discente. \\ [N.] - Sim.}

[A.A.] - Os professores recebem algum tipo de treinamento? O Daniel foi para lá, foi treinado para lidar com essas variações, com essas multiplicidades? Ou não?

[N.] - Tudo isso está sendo no processo. Temos um treinamento mais formalizado para o uso das tecnologias digitais. $\mathrm{O}$ uso dessas chamadas novas tecnologias, mas principalmente o que chamamos de uma abordagem meta-presencial, que é a possibilidade do docente se multiplicar na rede. Isso não é somente uma questão de eficiência, mas também para ajudar muito à autoinstrução dos alunos. Porque uma das demonstrações mais difundidas em geral, e pouco entendidas, é que a forma mais ineficiente de aprendizado é a aula clássica. Com variações em diferentes situações. Por exemplo, certas áreas têm que treinar uma certa retórica, uma certa oralidade, mas, na maioria das áreas de formação, é a forma mais ineficiente. Você tem que criar dispositivos que tornem a aula mais atraente. Mas nada substitui a capacidade do sujeito de buscar a informação ou conteúdo necessário de um modo orientado. Então, isso que você está falando é correto, os docentes que entram na universidade não são treinados para serem orientadores, mentores, mediadores, são treinados para serem - quer dizer, quando são treinados - para serem transmissores de conteúdo, não é?

[A.A.] - Eu tinha uma pergunta, confesso que li os documentos muito rapidamente e fiquei com uma dúvida. Não sei se a leitura rápida não me permitiu apreender. A universidade moderna, o modelo prussiano lá de Berlim, é construída de uma associação muito estreita entre ensino e pesquisa.

$$
\text { [N.] - Sim. }
$$

[A.A.] - É muito claro nos documentos que vocês produziram o ensino, mas, e a pesquisa? Como fica a pesquisa? Pesquisa-se o quê? Como essa pesquisa é veiculada? O que querem obter com o resultado da pesquisa? Também querem mudar isso? Fico com a impressão - não estou querendo de forma nenhuma criticar - mas certa pesquisa que pode ser socialmente orientada, é isso? O sujeito que faz física de partículas tem lugar lá? Ou não tem lugar? Um teórico, não o experimental, como fica? Isso confesso que para mim ficou um pouco nebuloso.

[N.] - As universidades em geral têm institucionalmente pouquíssimo controle sobre isso no mundo inteiro. A organização da pesquisa é muito feita por indução, em especial financeira e institucional. São editais, grupos que se organizam, mas você não vê nas universidades, e no Brasil menos ainda, investimentos para a formação de linhas de pesquisa específicas. Estamos num estágio ainda muito inicial, mas uma coisa aconteceu aí e é que estamos com um corpo docente $100 \%$ de doutores, acho que somos a única universidade federal. Nós e a Federal do ABC. Não por coincidência, são as únicas duas universidades brasileiras com regime de ciclos exclusivo. Acredito que essa abertura para a captação de docentes em áreas interdisciplinares, quer dizer, não fizemos concurso para física de partículas, sequer fizemos concurso para física. Até agora fizemos em áreas de ciência. Apareceram, temos dois físicos lá, um deles a especialidade é partículas. Cada um deles tem 
trazido as suas redes. Como são pessoas em sua maioria recém-doutores, estão ajustando muito as próprias pautas. Alguns deles têm uma produção científica bem razoável nas redes que trouxeram. Já tivemos capa da Nature com um professor nosso que estuda algo que a região é profusa, que é a floresta de mata atlântica. $\mathrm{O}$ grupo de oceanologia é um grupo muito forte. Neste momento estamos precisando ainda ter mais gente para poder fazer algumas catálises nesse processo. Provavelmente, o pessoal mais da área de humanas e sociais vai ajustar a sua pauta aos temas do território. Outras áreas terão que ajustar as suas pautas ao território se as suas redes científicas se interessarem. Por exemplo, o que acho que está acontecendo e acho que é patente isso, é que o próprio modelo da universidade se torne um objeto de investigação e de estudo.

Por exemplo, a pessoa que é físico de partículas está muito no ensino das ciências, quer dizer, como um modelo dessa natureza. Quer dizer, que perfil produz em termos de ensino de ciências? No Brasil, não há tradição institucional de organizar pela instituição a produção científica. Outros países têm. Mas por um problema que acho ser um problema nacional que é que o Brasil, para expandir o parque científico, criou relações individuais do pesquisador com as instituições de fomento. As relações não são institucionais. Você é pesquisador do CNPq, então você é um bolsista e responde direto ao CNPq. Se você entra num edital universal, CNPq. Inclusive, a conta é sua, é uma conta universal. Isso eu acho que não é assim em outros países de vanguarda na produção científica no mundo. Claro, o pesquisador elabora, propõe, participa, mas é a instituição que incorpora a responsabilidade e as instituições competem. Por isso produzem linhas de pesquisa inteiras. Aqui, até mesmo o formato da linha de pesquisa inteira, que é dos programas integrados, dos INCTIs, do Milênio, do Pronex, é pautado nos pesquisadores, produz redes de pesquisadores individuais. Eu não tenho inclusive nem visto uma discussão sobre isso. Mas, de qualquer maneira, acho que esse modelo é mais fomentador da incorporação da pesquisa no ensino do que o modelo convencional, porque tem espaço e interesse para os docentes incorporarem o que estão produzindo de conhecimento.

[A.A.] - Quer dizer, de certa maneira, não seria talvez equivocado pensar que para a pesquisa dar certo vai ter que de alguma maneira incorporar o território, a sociedade, os conhecimentos locais. Tem que haver algum tipo de diálogo, se não, vai ser muito difícil funcionar pelo menos globalmente.

[N.] - E também nós não temos a tradição que outros países também têm, de produzir investimentos pesados transformadores de certa realidade. Isso aconteceu em momentos muito específicos, por exemplo na Unicamp. Isso aconteceu ali, mas é muito raro. E é diferente, em outros países, não, você encontra grandes centros de produção focalizados totalmente fora dos eixos. Mas o Brasil nunca concebeu esse tipo de intervenção e as que foram feitas, foram malfeitas. Sei que quem trabalha com a questão da história recente desses processos tem essa avaliação crítica. E outra coisa, temos uma tradição de não fomentar a competitividade. O Brasil é capaz de produzir um grande plano de expansão das universidades em que todas receberam, mas receberam proporcionalmente, o que quer dizer que nenhuma apresentou um projeto inteiro que foi inteiramente aprovado. Estou me referindo ao REUNI. O REUNI, que poderia ser equivalente àquela grande agregação que a Alemanha fez, os dez grandes centros. A França também fez os polos e a Inglaterra também fez.

\section{[A.A.] - Aqui não.}

[N.] - Aqui não, porque o resultado é que se investiram 6 bilhões de reais na expansão das universidades, em que todas participaram de alguma forma com projetos que inclusive não tinham equivalência, não tinham foco. O pensamento estratégico não faz parte disso, quer dizer, predomina o pensamento político. Tem esse elemento aí.

[A.A.] - Para finalizar, qual seria o grande desafio que você vê a curto prazo na Federal do Sul da Bahia? Tem?

[N.] - Tem um seríssimo; desde 2014 não fazemos concurso. 


\section{[A.A.] - Concurso.}

[N.] - Tínhamos um plano de implantação de 150 vagas de concurso a cada ano, fizemos os concursos para as primeiras 150 vagas. Incorporamos alguns professores redistribuídos. Estamos com 180 professores. A cada ano foram entrando cerca de 900 alunos, estamos com 3000 alunos e mantendo o corpo docente inicial, em função da suspensão dos concursos, isso desde 2015, 2016, agora em 2017. Não, isso é uma ameaça pronta e direta. Se não fizermos concurso de imediato, no próximo mês ou em dois meses, é simplesmente a coisa física apenas. Não vamos ter docentes para completar a formação dos alunos que já estão. Além disso, os cortes. Os cortes são muito graves, são sérios. Nas universidades que já estão em estado estacionário, os cortes podem significar restrição de atividades em alguns pontos, mas você tem um contingente de alunos que entram e outros concluem. No nosso caso, não, simplesmente precisamos de um financiamento que é crescente, pois a universidade está em implantação. No caso, o governo federal tem a lógica do corte, do contingenciamento, e o nosso orçamento não pode nem ficar estacionário e menos do que estacionário está sendo decrescente. Isso é uma ameaça imediata. Apesar, deixe-me só acrescentar isso, que esse modelo tem elementos de eficiência inclusive institucional que distanciam do modelo... As taxas de evasão são muito pequenas. A razão aluno-professor é muito elevada, a integração nos territórios é muito alta. Os problemas na região estão sendo tratados na instituição. Preenchemos com folga um conjunto de dimensões e critérios, requisitos, que em tese deveriam favorecer até um apoio maior à instituição, até porque é um experimento ou um protótipo institucional. Isso infelizmente não tem ocorrido. 